\title{
Transcription of plasmid DNA: Influence of plasmid DNA/polyethylenimine complex formation
}

\author{
Isabelle Honoré $^{\text {a }}$, Stéphanie Grosse ${ }^{\text {a }}$, Natacha Frison ${ }^{\mathrm{b}}$, Florence Favatier ${ }^{\mathrm{a}}$, \\ Michel Monsigny ${ }^{\mathrm{b}}$, Isabelle Fajac ${ }^{\mathrm{a}, *}$ \\ ${ }^{a}$ Université Paris-Descartes, Faculté de Médecine, AP-HP, Hôpital Cochin, EA 2511, Paris, France \\ ${ }^{\mathrm{b}}$ Vectorologie et trafic intracellulaire, Centre de Biophysique Moléculaire, CNRS et Université d'Orléans, Orléans, France
}

\begin{abstract}
Polyethylenimine (PEI) is one of the most potent non-viral vectors. We have developed a lactosylated PEI (Lac-PEI) to enhance cell-specific transfection and have shown that Lac-PEI is more efficient than unsubstituted PEI for gene transfer into immortalized cystic fibrosis airway epithelial $\Sigma$ CFTE29o-cells. As both intact PEI/plasmid and Lac-PEI/plasmid complexes are found in the cell nucleus, we have investigated the transcription efficiency of the plasmid complexed with PEI or Lac-PEI, according to the polymer nitrogen/DNA phosphate (N/P) ratio (from 0 to 20). The initiation of transgene transcription was analyzed in an acellular nuclease S1 transcription assay. For both PEI and Lac-PEI complexes, transcription efficiency varied with the N/P ratio of the complexes. Transcription inhibition was observed when plasmid DNA was either loosely $(\mathrm{N} / \mathrm{P}<5)$ or tightly condensed (N/P $>15$ ). For an N/P ratio of 5 and up to 15 , transcription of the complexed plasmid was as efficient as that of the free plasmid. Similar results were observed when gene expression was studied after nuclear microinjection of the complexes into ZCFTE29o-cells. Our study shows that condensation of DNA influences the accessibility of the plasmid to the transcription machinery. Interestingly, the charge ratios that allow the most efficient transcription are those usually known to be the most efficient for gene transfer in vitro and in vivo.
\end{abstract}

Keywords: Polyethylenimine; Lactosylated polyethylenimine; Transcription; Cystic fibrosis

* Corresponding author. Lab. Physiol. Respir., Faculté Cochin, 24 rue du fg St-Jacques, 75679 Paris Cedex 14, France. Tel.: +33 144 4123 30; fax: +33144412333.

E-mail address: ifajac@cochin.univ-paris5.fr (I. Fajac).

\section{Introduction}

Gene delivery to the airway epithelium is a major goal for various respiratory disorders, including cystic fibrosis (CF), an autosomal recessive disorder due to mutations in the CFTR (Cystic Fibrosis Transmembrane Conductance Regulator) gene. However, despite thorough basic research and numerous clinical trials 
with viral and non-viral vectors, gene therapy successes so far have been rare. Cationic polymers such as polylysine or polyethylenimine (PEI) are non-viral vectors that interact with plasmids to form a compact particle thanks to electrostatic interactions. These self-assembling systems are an attractive long term solution because they are easily manufactured, able to carry large nucleic acid constructs and display low toxicity and immunogenicity [1]. The use of these polymerbased vectors is currently limited by their low gene delivery efficiency. One of the critical parameters for complex efficiency is the charge ratio of polycation to DNA that influences the size, the surface charge of the complexes and their intracellular trafficking [2].

PEI, which has endosomolytic properties [3], is one of the most potent non-viral vectors so far. We have substituted PEI with lactose residues in order to target cell-surface sugar-specific receptors and thus increase the binding of complexes to the cell surface [4]. We have shown that lactosylated PEI (Lac-PEI) is more efficient and less toxic than unsubstituted PEI for gene transfer into airway epithelial cells [5]. When studying the intracellular route of PEI complexes, we and others have found plasmid/PEI [5-7] and plasmid/Lac-PEI [5] as intact complexes in the nucleus. Then, the final step in the gene delivery process, i.e., plasmid transcription, is thought to take place and the complexed plasmid should be accessible to the transcription machinery. Besides influencing various critical parameters such as the size, the surface charge or the solubility of the complexes, the charge ratio of polycation to DNA influences the tightness of polycation/DNA complex. It could be assumed that a too tight condensation of the plasmid would prevent its access to the transcription machinery. Therefore, we have investigated the transcription efficiency of the plasmid complexed with PEI and Lac-PEI, according to the charge ratios of polycation to DNA.

\section{Materials and methods}

\subsection{Lactosylated polyethylenimine and formation of the complexes}

Five percent of the amino groups of polyethylenimine (PEI) (25 kDa, branched polymer; Sigma, St.
Louis, MO, USA) were substituted by a lactosylthiocarbamoyl residue, as previously described [4]. Briefly, to a solution of PEI dissolved in water $(10 \mathrm{mg} / \mathrm{ml})$, lactosyl phenylisothiocyanate $(12 \mu \mathrm{mol})$ [8,9] dissolved in $1 \mathrm{ml}$ of a $1: 1$ ethanol/water mixture was added and the solution was stirred for $30 \mathrm{~min}$ at room temperature. Under such conditions, the free lactosyl phenylisothiocyanate was no longer detectable upon thin-layer chromatography on silica gel plates using a $100: 30: 10: 10: 3$ ethanol/water/ $n$-butanol/pyridine/ acetic acid ( $\mathrm{vol} / \mathrm{vol})$ mixture. Upon removal of the ethanol under reduced pressure, the water solution was freeze-dried.

Three expression plasmids were used : pCMVLuc (pUT 650, $5.15 \mathrm{~kb}$; Cayla, Toulouse, France), pCMVGFP (pGFPemd-cmv; 4.80 kb; Packard, Meriden, CT, USA) and pCMVCFTR (10 kb) which include genes encoding the firefly luciferase, the green fluorescent protein (GFP) and the CFTR protein, respectively, under the control of the human cytomegalovirus (CMV) promoter. On the day of transfection, the plasmid and a given amount of lactosylated PEI (Lac-PEI) or unsubstituted PEI in order to obtain a chosen PEI nitrogen/DNA phosphorous $(\mathrm{N} / \mathrm{P})$ charge ratio between 0.5 and 20 (from a stock solution of PEI, $30 \mathrm{mM}$ in nitrogen) were separately diluted into $25 \mu \mathrm{l}$ of $150 \mathrm{mM} \mathrm{NaCl}$, mixed together and allowed to incubate at room temperature for $10 \mathrm{~min}$.

\subsection{Transcription assay}

To investigate the putative inhibition of transcription efficiency deriving from the condensation of DNA with Lac- or unsubstituted PEI, a nuclease S1 transcription assay adapted from Sambrook et al. [10] and previously described in Grosse et al. [11], was used. Briefly, Lac-PEI/ or unsubstituted PEI/plasmid DNA complexes were generated as described above. Free plasmid DNA (75 ng) or complexes were incubated with HeLa cell nuclear extracts (HelaScribe, Promega, Madison, WI, USA) to allow the formation of the preinitiation complex. Transcription was then initiated by adding NTPs and allowed to proceed for $30 \mathrm{~min}$ at $30{ }^{\circ} \mathrm{C}$. After phenol-chloroform extraction, the transcripts were hybridized overnight at $42{ }^{\circ} \mathrm{C}$ with $\left[{ }^{32} \mathrm{P}\right]$-labeled $(10,000 \mathrm{cpm} / \mathrm{assay}) 60$-mer oligonucleotide corre- 
sponding to the CMV sequence (from -20 to +40 ) of either pCMVLuc, pCMVGFP or pCMVCFTR. The single-stranded DNA was then digested with $100 \mathrm{U}$ of nuclease S1 (Amersham Pharmacia Biotech, Piscataway, NJ, USA). The reaction was stopped by adding $10 \mu \mathrm{g}$ of tRNA (Roche Diagnostics, Mannheim, Germany) and loaded on to an $8 \%$ polyacrylamide gel. A quantification of the transcription activity obtained on five independent experiments was done using a Bio-imaging analyzer and expressed as means \pm SEM in arbitrary units.

\subsection{Intracellular plasmid microinjections}

The immortalized, human tracheal epithelial ¿CFTE29o-cells, kindly given by D.C. Gruenert (University of Vermont, Burlington, VT, USA), were derived from a $\mathrm{CF}$ patient homozygous for the $\triangle$ F508 CFTR mutation and have no cAMPdependent chloride transport [12]. They were grown on CELLocate microgrid coverslips (Eppendorf, Hamburg, Germany) and microinjected in the nucleus or the cytoplasm, as previously described [12]. Briefly, free plasmid DNA pCMVGFP (50 $\mathrm{ng} / \mu \mathrm{l}$ in $\mathrm{H}_{2} \mathrm{O}$ ) or plasmid DNA/Lac- or unsubstituted PEI complexes were diluted in a $0.5 \%$ tetramethylrhodamine isothiocyanate-dextran $(155 \mathrm{kDa})$ solution and microinjected under visual control on a Nikon Diaphot inverted phase-contrast microscope, using a Micromanipulator 5170 and a Microinjector 5242 (Eppendorf). Injections were performed with the $Z$ (depth) limit option, using a 0.2-s injection time and 150-hectopascal injection pressure via glass micropipettes (Femtotips; Eppendorf). In order to verify that complexes exited the micropipettes, microinjection of biotinylated plasmid DNA complexed with PEI or Lac-PEI $(\mathrm{N} / \mathrm{P}=0$ or 10$)$ and diluted in a $0.5 \%$ FITC-dextran solution were performed. After labeling of the biotinylated plasmid with rhodamine-conjugated streptavidin, complexes were observed, as expected, in the cell nuclei or cytoplasm, according to the site of microinjection. Twenty-four hours after microinjection of pCMVGFP/Lac- or unsubstituted PEI complexes, cells were fixed, mounted in Vectashield-DAPI solution (Vector, Burlingame, CA, USA) and analyzed using an MRC-1024 BioRad confocal system (Her- cules, CA, USA) mounted on a Diaphot 300 inverted microscope. The krypton/argon laser was tuned to produce $488-\mathrm{nm}$ and $568-\mathrm{nm}$ excitation wavelengths. Serial sections collected at increments of $0.5-\mu \mathrm{m}$ thick were obtained. The presence of tetramethylrhodamine isothiocyanate-dextran in the injected solution allowed the determination of the exact number of injected cells and the localization of microinjection. The overnight survival rate of injected cells was calculated (usually about 50\%) and the number of GFP-expressing cells was determined.

\subsection{Visualization of complexes by agarose gel electrophoresis and electron microscopy}

Plasmid pCMVLuc/Lac-PEI and /PEI complexes were prepared as described above. Electrophoresis was carried out in $0.6 \%$ agarose gels containing ethidium bromide $(0.1 \mu \mathrm{g} / \mathrm{ml})$ with a potential of $80 \mathrm{~V}$. The DNA localization was visualized by UV transillumination.

Complex morphology was investigated by transmission electron microscopy (TEM). Seven- $\mu$ d drops of freshly prepared complexes were placed on 300mesh copper/rhodium grids (TAAB Laboratories Equipment, Berks, UK) for $1 \mathrm{~min}$. Solution was wiped off with filter paper and the grids were stained with $30 \mu \mathrm{l}$ of $1 \%$ aqueous uranyl acetate for $30 \mathrm{~s}$. After removal of the solution with filter paper, grids were rinsed in distilled water and allowed to dry. Grids were observed by using a Philips BioTwin CM 120 TEM electron microscope (FEI, Cambridge, $\mathrm{UK}$ ) operated at $60 \mathrm{KV}$.

\subsection{Size and zeta potential of the complexes}

Plasmid/Lac-PEI and /PEI complexes were prepared by using $10 \mu \mathrm{g}$ of pCMVLuc plasmid and then, complexes were diluted in $150 \mathrm{mM} \mathrm{NaCl}$ to a final volume of $1 \mathrm{ml}$. Both particle size and zeta potential were determined in 3 independent experiments by dynamic light scattering using a Zetasizer 3000 (Malvern instruments, Orsay, France) with the following specifications: automatic sampling time, 10 measurements per sample; medium viscosity: $0.89 \mathrm{cP}$; refractive index (RI) medium: 1.33 ; dielectric constant: 79 ; temperature: $25{ }^{\circ} \mathrm{C}$, beam mode: $\mathrm{F}(\mathrm{Ka})=$ 1.50 (Smoluchowsky) [13]. 


\section{Results}

\subsection{Transcription efficiency of plasmid DNA com- plexed with Lac-PEI or unsubstituted PEI}

Using an S1 nuclease transcription assay and HeLa cell nuclear extracts, the transcription efficiency of PEI and Lac-PEI complexes was studied according to the N/P ratios. For both PEI and Lac-PEI complexes, initiation of transcription was very low with complexes at $\mathrm{N} / \mathrm{P}=2.5$ (Fig. 1). The transcription of complexes made with PEI was maximal with an N/P ratio range from 5 to 15 . At higher $\mathrm{N} / \mathrm{P}$ ratios, the transcription efficiency decreased (Fig. 1A). For LacPEI complexes, the most efficient transcription was obtained at $\mathrm{N} / \mathrm{P}=10$ and 15 , and also decreased at higher N/P ratios (Fig. 1B and C). The N/P ratio of 10 allowed the highest transcription of the plasmid complexed with either PEI or Lac-PEI. Transcription efficiencies of PEI or Lac-PEI complexes at $\mathrm{N} / \mathrm{P}=10$ were then compared to that obtained with the free pCMVLuc plasmid. Initiation of free pCMVLuc transcription was efficient and when the transcription of pCMVLuc complexed with PEI or Lac-PEI was compared to the one obtained for free pCMVLuc, a similar magnitude of transcription was observed (Fig. 2A and B). As the size or the type of the plasmid could influence the transcription efficiency, the transcription efficiencies of free and complexed pCMVGFP (4.8 $\mathrm{kb})$ and of pCMVCFTR $(10 \mathrm{~kb})$ were investigated (Fig. 2C and D). Both (pCMVGFP and pCMVCFTR) plasmids, either free or complexed with PEI or LacPEI $(\mathrm{N} / \mathrm{P}=10)$, were transcribed with efficiency. However, the transcription efficiency of complexed pCMVCFTR was slightly lower, as compared to the one observed for free pCMVCFTR.

The number of cells expressing GFP was determined $24 \mathrm{~h}$ after nuclear microinjection of free pCMVGFP plasmid and of pCMVGFP plasmid complexed with PEI or Lac-PEI at different $\mathrm{N} / \mathrm{P}$ ratios (2.5 to 20) (Fig. 3). For both PEI and Lac-PEI complexes, the number of cells expressing GFP varied with the $\mathrm{N} / \mathrm{P}$ ratio. The highest gene transfer efficiency was obtained for $\mathrm{N} / \mathrm{P}$ ratios of 5 and 10 for Lac-PEI and PEI complexes, respectively. Under such conditions, $93 \pm 2 \%$ and $90 \pm 4 \%$ of cells expressed GFP, respectively. When the free pCMVGFP plasmid was microinjected into the nucleus, $98 \pm 2 \%$ of cells

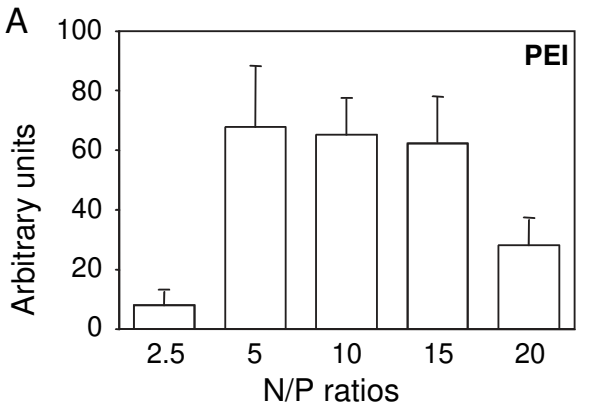

B
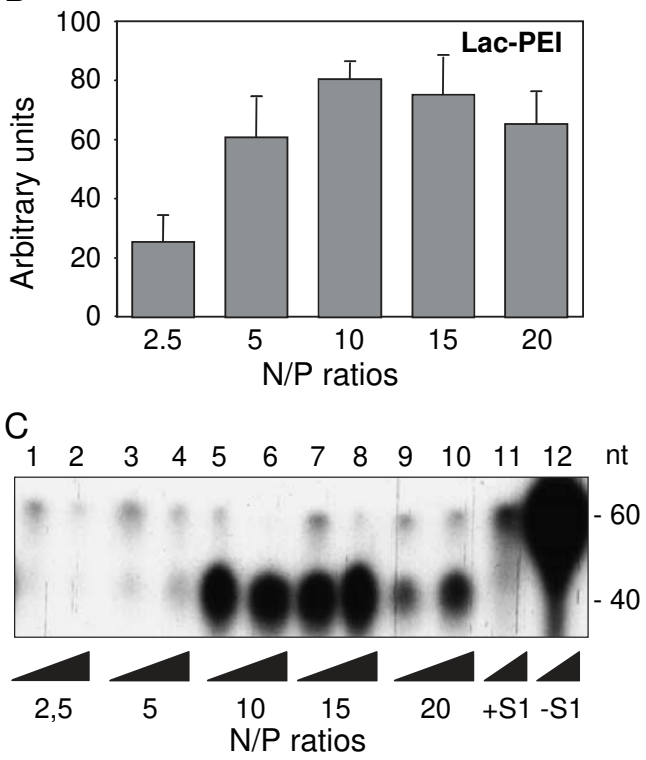

Fig. 1. Transcription efficiency of plasmid/PEI and /Lac-PEI complexes at varying $\mathrm{N} / \mathrm{P}$ ratios. The pCMVLuc plasmid (75 ng) was complexed with the desired amount of PEI or Lac-PEI to obtain a chosen N/P ratio from 2.5 to 20 and tested for transcription activity in a nuclease S1 assay. (A) and (B): A quantification of the transcription activity was done using a Bio-imaging analyzer. The means \pm SEM of three independent experiments are indicated. (C) An assay of transcription efficiency of plasmid DNA complexed with Lac-PEI : lanes 1, 3, 5, 7, $9: 1.5 \mu 1$ of HeLa cell nuclear extracts and lanes 2, 4, 6, $810: 3 \mu \mathrm{l}$ of HeLa cell nuclear extracts; control lanes 11 and 12 represent the nuclease S1 (100 U)-digested and the undigested radio labeled probe, respectively. (nt : nucleotide).

expressed GFP. There was no statistically significant difference (non-parametric Mann-Whitney $U$ test) between the number of cells expressing GFP upon nuclear microinjection of the free plasmid and of the plasmid complexed with PEI or Lac-PEI at the optimal N/P ratios. 

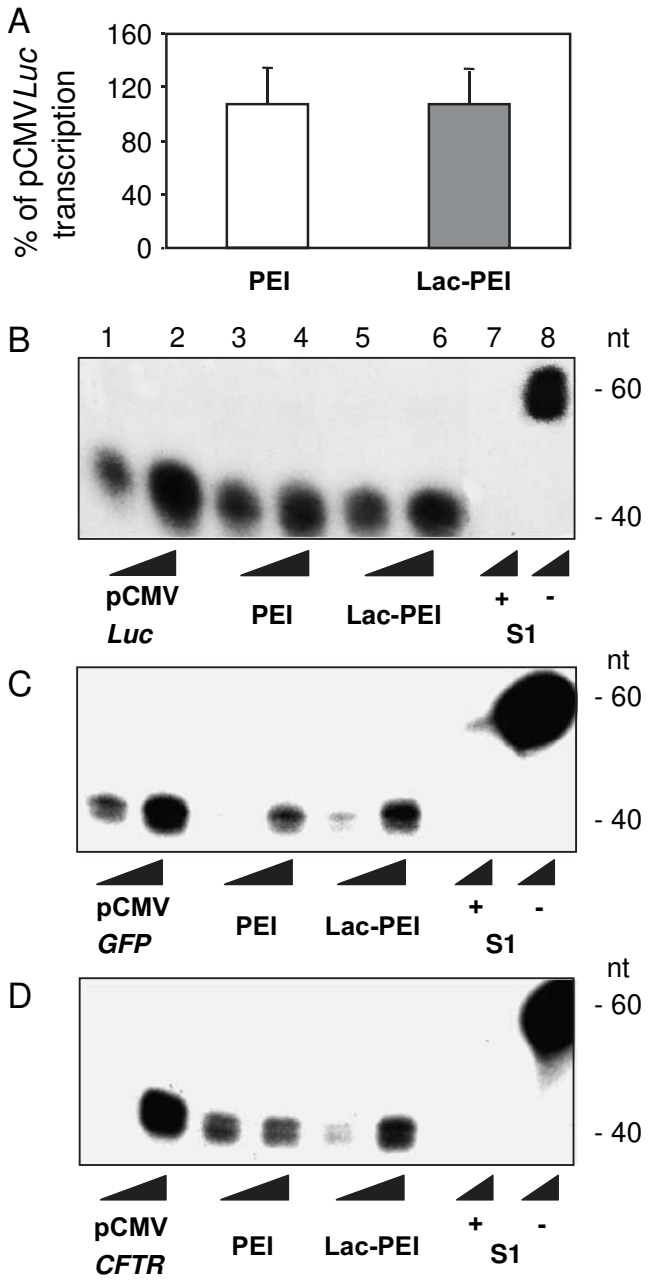

Fig. 2. Transcription efficiency of vector-free plasmid and plasmid complexed with PEI and Lac-PEI. The pCMVLuc (A and B), pCMVGFP (C) and pCMVCFTR (D) plasmids (75 ng) were complexed with the desired amount of PEI or Lac-PEI to obtain a N/P ratio of 10 and tested for transcription activity in a nuclease S1 assay. (A) A quantification of the transcription activity was done using a Bio-imaging analyzer. The means \pm SEM of five independent experiments are indicated and expressed as the percentages of transcription activity obtained for free pCMVLuc. (B, $\mathrm{C}$ and D): Assays of transcription efficiencies: lanes 1, 3, 5: $1.5 \mu \mathrm{l}$ of HeLa cell nuclear extracts and lanes 2, 4, 6: $3 \mu \mathrm{l}$ of HeLa cell nuclear extracts; control lanes 7 and 8 represent the nuclease S1 (100U)-digested and the undigested radiolabeled probe, respectively. (nt: nucleotide).

Similarly, the number of cells expressing GFP was determined $24 \mathrm{~h}$ after intracytoplasmic microinjection of free pCMVGFP plasmid and of pCMVGFP plasmid complexed with PEI or Lac-PEI at different $\mathrm{N} / \mathrm{P}$ ratios (2.5 to 20) (Fig. 3). Results were similar to those observed after nuclear microinjection: for both PEI and Lac-PEI complexes, the number of cells expressing GFP varied with the N/P ratio and the highest gene transfer efficiency was obtained for N/P ratios of 10 for both complexes. However, the numbers of transfected cells upon intracytoplasmic microinjection were much lower $(27 \pm 9 \%$ and $42 \pm 15 \%$ for PEI and Lac-PEI complexes at $\mathrm{N} / \mathrm{P}=10$, respectively), as compared with those obtained upon nuclear microinjection. When the free pCMVGFP plasmid was microinjected into the cytoplasm, $20 \pm 7 \%$ of cells expressed GFP. There was no statistically significant difference (non-parametric Mann-Whitney $U$ test) between the number of cells expressing GFP upon intracytoplasmic microinjection of the free plasmid and of the plasmid complexed with PEI or Lac$\mathrm{PEI}$ at the optimal $\mathrm{N} / \mathrm{P}$ ratios.

\subsection{Physico-chemical properties of PEI and Lac-PEI complexes}

In order to characterize the process of the complex formation, plasmid DNA and complexes with different $\mathrm{N} / \mathrm{P}$ ratios $(0.5$ to 20$)$ were subjected to agarose gel electrophoresis (Fig. 4). Free DNA was observed as two fluorescent bands corresponding to the supercoiled and circular forms of the plasmid. When plasmid DNA was complexed with PEI or Lac-PEI at low $\mathrm{N} / \mathrm{P}$ ratios, a fraction of plasmid was still free to migrate into the gel. Another fraction of plasmid DNA was trapped in the application slot indicating that complexes were larger in size and/or less negatively charged than free DNA. When complexes were made with PEI and Lac-PEI at N/P ratios of 2 and 2.5 , respectively, no DNA migrated into the gel, indicating that all the plasmid DNA was complexed with the vector. At higher N/P ratios, the intensity of the ethidium bromide fluorescence in the application slot was reduced and completely disappeared for PEI complexes, showing that the compaction did not let the dye entering in the complexes.

The size range of PEI and Lac-PEI complexes at different $\mathrm{N} / \mathrm{P}$ ratios (0 to 20 ) was determined by dynamic light scattering (Fig. 5A). For N/P ratios $\leq 5$, 5 , PEI and Lac-PEI complexes could not be accurately analyzed due to an incomplete complex formation and a too broad complex size range. At $\mathrm{N} / \mathrm{P}=10$, 

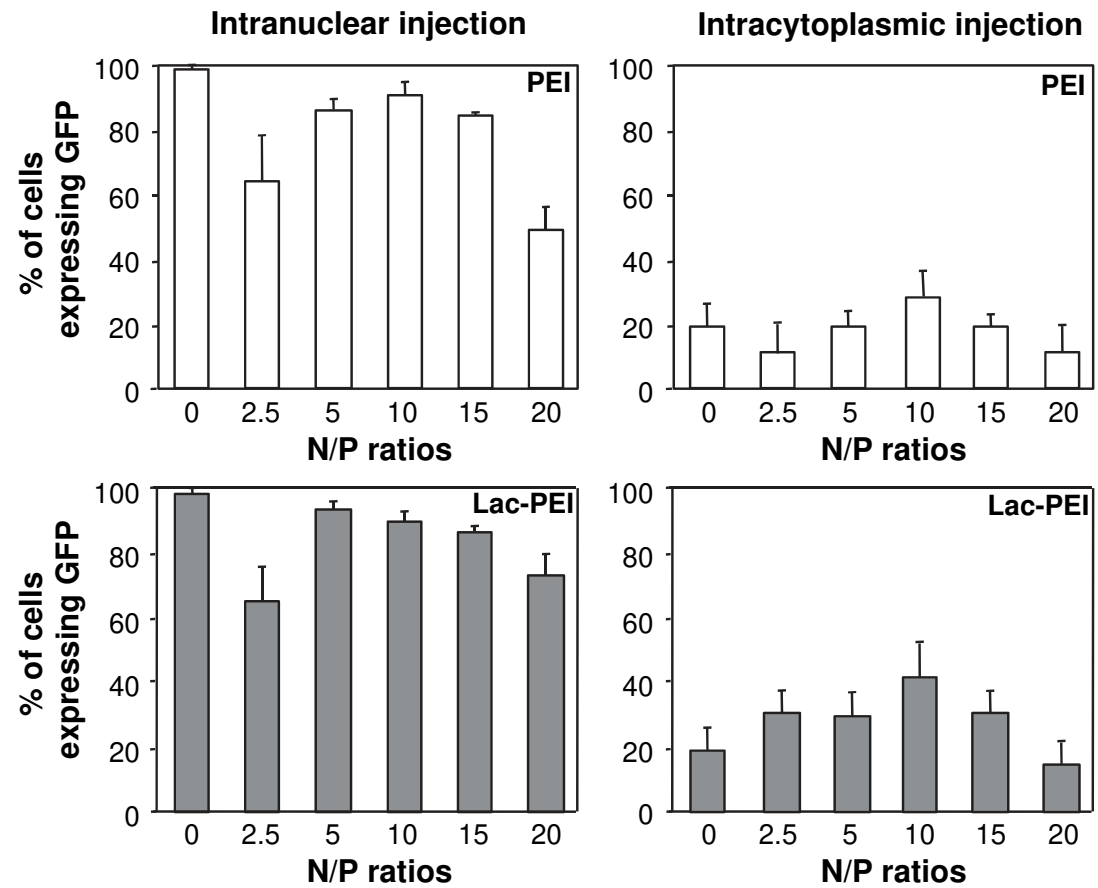

Fig. 3. Expression of GFP by $\Sigma$ CFTE29o-cells upon intracellular microinjections of pCMVGFP plasmid complexed with PEI or Lac-PEI at varying N/P ratios. The pCMVGFP plasmid complexed with the desired amount of PEI or Lac-PEI to obtain a chosen N/P ratio from 0 to 20 was diluted in a tetramethylrhodamine isothiocyanate-dextran solution and microinjected into the nucleus or the cytoplasm of $\Sigma$ CFTE29o-cells. Twenty-four hours later, the number of cells expressing GFP and the total number of microinjected cells were determined by using a confocal microscope. Results are expressed as percentages of microinjected cells expressing GFP.

a relatively homogeneous size distribution was observed for both types of complexes : from 70 to $500 \mathrm{~nm}$, with a mean size of $200 \mathrm{~nm}$. With an N/P ratio of 15 , the size range of the plasmid/PEI complexes was similar to that obtained with a ratio of 10 , while the size range of the plasmid/Lac-PEI com-

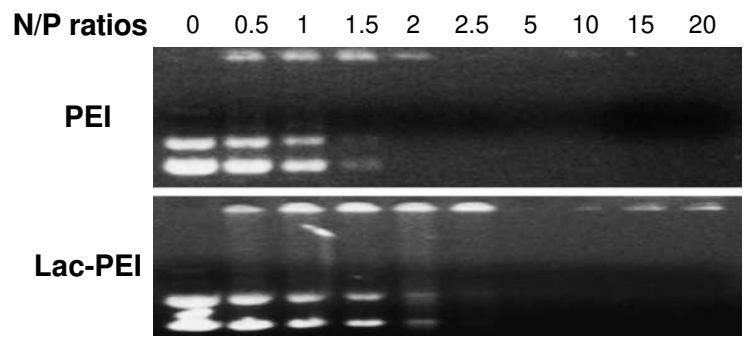

Fig. 4. Electrophoretic migration of pCMVLuc plasmid complexed with PEI or Lac-PEI at varying $\mathrm{N} / \mathrm{P}$ ratios. The $\mathrm{pCMVLuc}$ plasmid $(2.5 \mu \mathrm{g})$ was complexed with the desired amount of PEI or Lac-PEI to obtain a chosen N/P ratio from 0 to 20 . Samples were run on $0.6 \%$ agarose gel containing ethidium bromide and visualized on an ultraviolet transilluminator. plexes was clearly narrower (from 100 to $200 \mathrm{~nm}$ ). With an N/P ratio of 20 , the plasmid/PEI complexes were larger (from 200 to $500 \mathrm{~nm}$ ), while the size range of the plasmid/Lac-PEI complexes was slightly higher than those obtained with plasmid/Lac-PEI complexes ratio of 15 and smaller than those obtained with plasmid/Lac-PEI complexes ratio of 10 .

The zeta potential of PEI and Lac-PEI complexes was measured at different $\mathrm{N} / \mathrm{P}$ ratios (up to 20) (Fig. 5B). Plasmid/PEI complexes had a negative surface charge for low $\mathrm{N} / \mathrm{P}$ ratios up to 2 . At $\mathrm{N} / \mathrm{P}$ of 5 and above, the zeta potential became strongly positive and reached a maximal level of about $+40 \mathrm{mV}$ at ratios of 10 and above. For plasmid/Lac-PEI complexes, particles were negative for $\mathrm{N} / \mathrm{P}$ ratios up to 3 ; they were neutral at $\mathrm{N} / \mathrm{P}=3.5$ and had a maximal zeta potential level of $+30 \mathrm{mV}$ at ratios of 10 and above.

PEI and Lac-PEI complexes at $\mathrm{N} / \mathrm{P}$ ratio of 10 were observed by TEM (Fig. 5C). Their size as measured by TEM reflected the dispersity observed by dynamic light scattering. Various complex morpholo- 
A

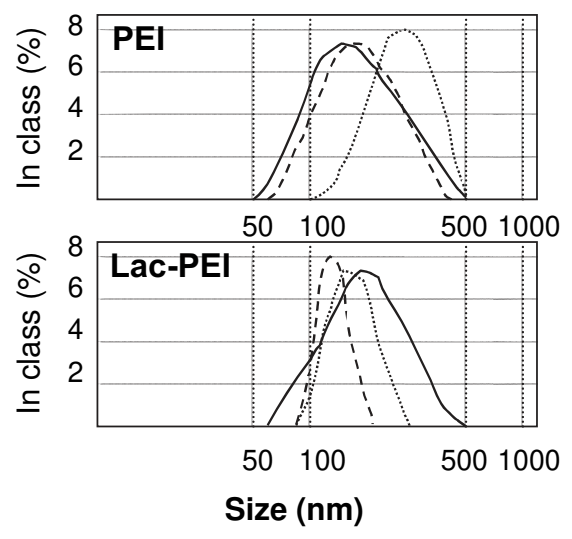

$\mathrm{B}$

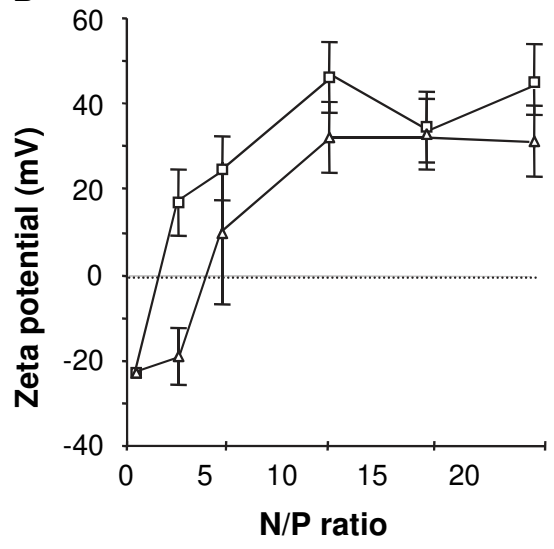

C
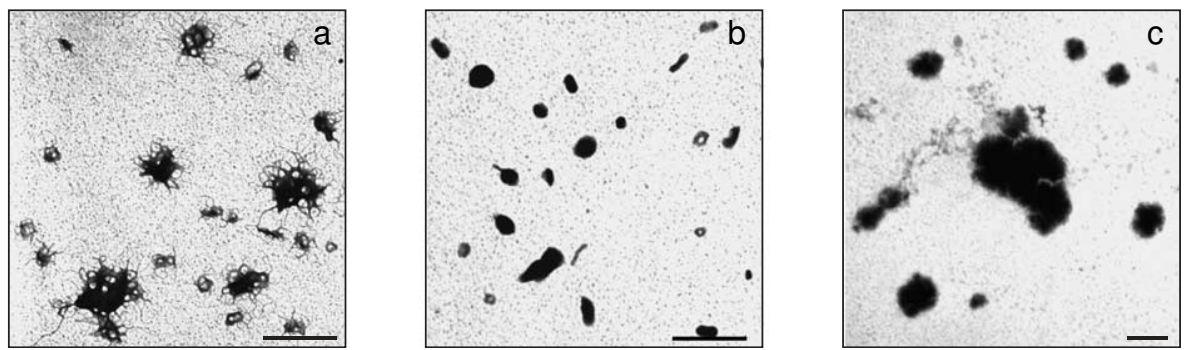

Fig. 5. Physicochemical characteristics of PEI and Lac-PEI complexes at varying N/P ratios. (A) Size of PEI and Lac-PEI complexes: $10 \mu \mathrm{g}$ of pCMVLuc plasmid were complexed with the desired amount of PEI or Lac-PEI to obtain a chosen N/P ratio of $10(-), 15(--)$ or $20(\cdots \cdots)$ and diluted in $150 \mathrm{mM} \mathrm{NaCl}$. Complex size was determined by dynamic light scattering. (B) Zeta potentials of PEI ( $\square$ ) and Lac-PEI $(\triangle)$ complexes: complexes were prepared as described above to obtain charge ratios from 0 to 20 and their surface potential was measured as described in Materials and methods. (C) Transmission electron micrographs of pCMVLuc/Lac-PEI complexes prepared at an N/P ratio of 10. Some complexes were not fully condensed (a), some were small and had a donut or rod shape (b), others were aggregated (c). Bars $=200 \mathrm{~nm}$.

gies were seen that were similar for both types of complexes: some complexes (around 25\%) appeared to be not fully condensed (Fig. 5Ca) and some loops radiating from the particle core were observed. Other complexes (around 50\%) were small and had a donut, rod, or even pretzel shape (Fig. 5Cb). Occasionally, some aggregated complexes (around 25\%) were also found (Fig. 5Cc).

\section{Discussion}

Gene delivery mediated by polycations is a multistep process in which the nuclear entry is one of the last and the major barriers to effective gene transfer. When a plasmid is delivered as a complex made with PEI or PEI derivatives, the exact mechanism of entry into the nucleus is still largely unknown. However,
plasmid/PEI complexes have been found inside the nucleus $[5,7]$ and disassembly of these plasmid/PEI complexes inside the nucleus has yet to be shown. Therefore, at this stage, transgene expression mainly depends on the access of the plasmid to the transcription machinery. Condensation of chromosomal DNA is a well known factor influencing gene transcription. Likewise, condensation of plasmid DNA by formation of complexes with PEI derivatives may influence its transcription. Because the plasmid condensation is mostly determined by the polymer/DNA ratio [14], we evaluated whether the efficiency of transcription varied with the $\mathrm{N} / \mathrm{P}$ ratio of the complexes, that is the PEI nitrogen $(\mathrm{N})$ per DNA phosphorous $(\mathrm{P})$ ratio.

In an acellular system, we found that the initiation of transcription varied with the $\mathrm{N} / \mathrm{P}$ ratio, the most efficient transcription being found at an $\mathrm{N} / \mathrm{P}$ ratio around 10 for either PEI or Lac-PEI complexes. The 
$\mathrm{N} / \mathrm{P}$ ratio is known to influence the size and surface charge of the complexes, their morphology and the extent of DNA condensation. At an N/P ratio of 10, we and others [15], have found that complexes had a size of 70-500 $\mathrm{nm}$ and a positive surface charge close to $+40 \mathrm{mV}$. It is unlikely that the size and the surface charge of the particles influence per se the efficiency of transcription, since those parameters were similar for complexes made at higher $\mathrm{N} / \mathrm{P}$ ratios and the transcription efficiency of such complexes was lower.

The extent of plasmid condensation might be a major factor determining the different transcription efficiencies observed with different $\mathrm{N} / \mathrm{P}$ ratios. One way to get an insight into the extent of plasmid condensation is to look at the shape of complexes. However, as observed by transmission electron microscopy, the morphology of both types of complexes at $\mathrm{N} / \mathrm{P}$ ratio of 10 , was rather heterogeneous : particles with loops of DNA radiating from the central core, particles with spherical and toroidal shapes, as well as aggregated particles. These complex morphologies have been previously described by others [16-18] and unfortunately did not lead to clear conclusions on the morphology and gene transfer efficiency relationship. Results obtained on DNA gel retardation may be more helpful to determine the extent of plasmid condensation. For PEI complexes at N/P ratios of 15 and 20 and in the presence of ethidium bromide, no fluorescence could be detected, indicating that the DNA was fully condensed because the dye was excluded [19]. This high DNA condensation is likely to prevent access to the transcription machinery, in agreement with the substantially reduced transcription efficiency observed for PEI complexes at N/P ratio of 20. In contrast, for Lac-PEI complexes, DNA could be detected in the application slot at all N/P ratios showing that even at high $\mathrm{N} / \mathrm{P}$ ratios, ethidium bromide could reach DNA into the condensed plasmid. In line with this finding, only a slight transcription inhibition was observed at the highest $\mathrm{N} / \mathrm{P}$ ratio, indicating that DNA complexed with Lac-PEI was accessible to the transcription machinery. Therefore, although the size and the surface charge of the particles were similar for PEI and Lac-PEI complexes, the glycosylation of PEI appears to slightly change the strength of its interaction with DNA.

The high compaction of plasmid DNA at high N/P ratios might explain the low transcription of plasmid
DNA observed at high N/P ratios by partly preventing the transcription machinery access. However, an inactivation of transcription enzymes by the free polymer present at high $\mathrm{N} / \mathrm{P}$ ratios might also play a role. A very inefficient transcription was observed at $\mathrm{N} / \mathrm{P}$ ratio of 2.5. This has been previously reported by Bieber et al. without any explanation [20]. It suggests that partially unwound DNA prevents an efficient transcription. Although we could not accurately measure the size of the complexes at N/P ratios $\leq 5$, others [15] have described polydisperse and large PEI complexes at those ratios. Large aggregates with low surface per volume ratio may also be inaccessible to the transcription machinery, therefore leading to low transcript numbers.

All these above mentioned findings were observed in an acellular system. Similar findings were observed in a cellular system, upon nuclear microinjections of the complexes. The most efficient gene transfer was obtained upon nuclear microinjection of complexes with $\mathrm{N} / \mathrm{P}$ ratios of $5-10$ which were the $\mathrm{N} / \mathrm{P}$ ratios that allowed the most efficient transcription. At these $\mathrm{N} / \mathrm{P}$ ratios, the efficiency of transcription was similar to that observed with the free plasmid, showing that the condensation of DNA did not prevent its access to the transcription machinery. For lower and higher N/ $\mathrm{P}$ ratios, the results obtained in an acellular system and in a cellular one upon nuclear microinjections of the complexes, suggest that in the microinjected cells that were not transfected, the low level of transcription was not sufficient to allow the expression and/or detection of GFP. When the number of transfected cells was studied upon intracytoplasmic microinjection, the gene transfer efficiency was low. However, a variation of gene transfer efficiency with the N/P ratios was observed, similar to that seen upon nuclear microinjection. This result suggests that the nuclear import of complexes is impeded to the same extent for all complexes, whatever the $\mathrm{N} / \mathrm{P}$ ratio used.

It has been previously shown that the $\mathrm{N} / \mathrm{P}$ ratio, by influencing the size and the surface charge of the complexes, plays a critical role in gene transfer efficiency. Gene transfer is optimal when particles are positively charged and able to bind to anionic cellsurface proteoglycans to be taken up by the cells $[17,21]$. A small particle size is also thought to favor receptor-mediated endocytosis for complexes made with ligand-conjugated polycations, to favor 
complex diffusibility in the cytoplasm and increase nuclear uptake [22]. This study shows that the N/P ratio, by influencing the condensation of DNA, also determines the accessibility of the plasmid to the transcription machinery. It is of interest, and rather encouraging, to note that the ratios allowing the most efficient transcription (5-15) are also those allowing the most efficient transfection rates in vitro $[3,6,18]$ and in vivo $[3,23]$.

To rationally design more potent vectors, the critical steps in the process of plasmid/PEI complex transport from the extracellular space into the nucleus have been investigated. The cell-targeting and the uptake of complexes, their endosome escape, their transport into the nucleus have been thoroughly studied $[2,24]$. As plasmid/PEI complexes do not appear to dissociate in the nucleus $[5,7]$, we have studied the final step of gene transfer, i.e., plasmid transcription, and have shown that it was modulated by the plasmid DNA/PEI complex formation. An inhibition of transcription was observed when the plasmid DNA was either loosely or tightly condensed. However, there was no transcription inhibition of the plasmid DNA complexed with PEI derivatives at the polymer to DNA ratio usually considered as the most efficient for gene transfer. This is fortunate and indicates that the design of a modified PEI allowing the uncoating of the plasmid is not necessary. It is likely that the most critical intracellular step that remains with PEI derivatives as vectors is the transport of the plasmid into the nucleus. The design of a modified PEI able to overcome this barrier is our next aim.

\section{Acknowledgements}

We are grateful to Guiti Thévenot (Laboratoire de Physiologie Respiratoire, IFR Alfred Jost, Paris) and Yolande Aron (Direction de la Recherche Clinique, AP-HP, Paris) for technical assistance, D.C. Gruenert for the gift of the ECFTE29o-cell line, and the Services Communs de Microscopie Confocale et de Cytométrie en Flux (IFR Alfred Jost, Paris). IH was funded by the Fondation pour la Recherche Médicale. This research was supported by the Association Vaincre la Mucoviscidose, the Chancellerie des Universités de Paris and the Institut National de la Santé et de la Recherche Médicale (CReS 4CR03F).

\section{References}

[1] S.C. De Smedt, J. Demeester, W.E. Hennink, Cationic polymer based gene delivery systems, Pharm. Res. 17 (2) (2000) $113-126$.

[2] M. Thomas, A.M. Klibanov, Non-viral gene therapy: polycation-mediated DNA delivery, Appl. Microbiol. Biotechnol. 62 (1) (2003) 27-34.

[3] O. Boussif, F. Lezoualc'h, M.A. Zanta, M.D. Mergny, D. Scherman, B. Demeneix, J.-P. Behr, A versatile vector for gene and oligonucleotide transfer into cells in culture and in vivo: polyethylenimine, Proc. Natl. Acad. Sci. U. S. A. 92 (1995) 7297-7301.

[4] I. Fajac, G. Thévenot, L. Bédouet, C. Danel, M. Riquet, M. Merten, C. Figarella, J. Dall'Ava-Santucci, M. Monsigny, P. Briand, Uptake of plasmid/glycosylated polymer complexes and gene transfer efficiency in differentiated airway epithelial cells, J. Gene Med. 5 (2003) 38-48.

[5] S. Grosse, Y. Aron, I. Honoré, G. Thévenot, C. Danel, A.C. Roche, M. Monsigny, I. Fajac, Lactosylated polyethylenimine for gene transfer into airway epithelial cells: role of the sugar moiety in cell delivery and intracellular trafficking of the complexes, J. Gene Med. 6 (2004) 345-356.

[6] H. Pollard, J.S. Remy, G. Loussouarn, S. Demolombe, J.P. Behr, D. Escande, Polyethylenimine but not cationic lipids promotes transgene delivery to the nucleus in mammalian cells, J. Biol. Chem. 273 (1998) 7507-7511.

[7] W.T. Godbey, K.K. Wu, A.G. Mikos, Tracking the intracellular path of poly(ethylenimine)/DNA complexes for gene delivery, Proc. Natl. Acad. Sci. U. S. A. 96 (9) (1999) 5177-5181.

[8] A.C. Roche, M. Barzilay, P. Midoux, S. Junqua, N. Sharon, M. Monsigny, Sugar-specific endocytosis of glycoproteins by Lewis lung carcinoma cells, J. Cell. Biochem. 22 (1983) 131-140.

[9] M. Monsigny, A.C. Roche, P. Midoux, Uptake of neoglycoproteins via membrane lectin(s) of L 1210 cells evidenced by quantitative flow cytofluorometry and drug targeting, Biol. Cell 51 (1984) 187-196.

[10] J. Sambrook, E. Fritsch, T. Maniatis, Molecular Cloning: A Laboratory Manual, Cold Spring Harbor Laboratory Press, Cold Spring Harbor, NY, 1989.

[11] S. Grosse, A. Tremeau-Bravard, Y. Aron, P. Briand, I. Fajac, Intracellular rate-limiting steps of gene transfer using glycosylated polylysines in cystic fibrosis airway epithelial cells, Gene Ther. 9 (2002) 1000-1007.

[12] K. Kunzelmann, E.M. Schwiebert, P.L. Zeitlin, W.-L. Kuo, B.A. Stanton, D.C. Gruenert, An immortalized cystic fibrosis tracheal epithelial cell line homozygous for the $\Delta$ F508 CFTR mutation, Am. J. Respir. Cell Mol. Biol. 8 (1993) 522-529.

[13] P. Erbacher, S. Zou, T. Bettinger, A.M. Steffan, J.S. Remy, Chitosan-based vector/DNA complexes for gene delivery: biophysical characteristics and transfection ability, Pharm. Res. 15 (9) (1998) 1332-1339.

[14] K. Minagawa, Y. Matsuzawa, K. Yoshikawa, M. Matsumoto, M. Doi, Direct observation of the biphasic conformational change of DNA induced by cationic polymers, FEBS Lett. $295(1-3)(1991) 67-69$. 
[15] P. Erbacher, T. Bettinger, P. Belguise-Valladier, S. Zou, J.L. Coll, J.P. Behr, J.S. Remy, Transfection and physical properties of various saccharide, poly(ethylene glycol), and antibodyderivatized polyethylenimines (PEI), J. Gene Med. 1 (3) (1999) 210-222.

[16] D.D. Dunlap, A. Maggi, M.R. Soria, L. Monaco, Nanoscopic structure of DNA condensed for gene delivery, Nucleic Acids Res. 25 (15) (1997) 3095-3101.

[17] M.X. Tang, F.C. Szoka, The influence of polymer structure on the interactions of cationic polymers with DNA and morphology of the resulting complexes, Gene Ther. 4 (8) (1997) 823-832.

[18] M. Ogris, P. Steinlein, M. Kursa, K. Mechtler, R. Kircheis, E. Wagner, The size of DNA/transferrin-PEI complexes is an important factor for gene expression in cultured cells, Gene Ther. 5 (10) (1998) 1425-1433.

[19] K. Kunath, A. von Harpe, D. Fischer, T. Kissel, GalactosePEI-DNA complexes for targeted gene delivery: degree of substitution affects complex size and transfection efficiency, J. Control. Release 88 (1) (2003) 159-172.
[20] T. Bieber, W. Meissner, S. Kostin, A. Niemann, H.P. Elsasser, Intracellular route and transcriptional competence of polyethylenimine-DNA complexes, J. Control. Release 82 (2-3) (2002) 441-454.

[21] K.A. Mislick, J.D. Baldeschwieler, Evidence for the role of proteoglycans in cation-mediated gene transfer, Proc. Natl. Acad. Sci. U. S. A. 93 (22) (1996) 12349-12354.

[22] R. Kircheis, L. Wightman, E. Wagner, Design and gene delivery activity of modified polyethylenimines, Adv. Drug Deliv. Rev. 53 (3) (2001) 341-358.

[23] A. Bragonzi, G. Dina, A. Villa, G. Calori, A. Biffi, C. Bordignon, B.M. Assael, M. Conese, Biodistribution and transgene expression with nonviral cationic vector/DNA complexes in the lungs, Gene Ther. 7 (20) (2000) 1753-1760.

[24] W.T. Godbey, K.K. Wu, A.G. Mikos, Poly(ethylenimine) and its role in gene delivery, J. Control. Release 60 (2-3) (1999) $149-160$. 